\title{
About the Course of Schizoaffective Psychoses
}

\author{
H.M. van Praag and L. Nijo
}

\begin{abstract}
This study involves a program that was developed to determine whether there is a need for the category of schizoaffective disorders. The data suggest that the term schizoaffective pychoses should be upheld as a collective name for the group of the functional "mixed psychoses" between the schizophrenic group and that of the (non-psychotic) manic-depressive syndromes, and that like the group of schizophrenic psychoses, that of the schizoaffective psychoses is a heterogeneous group in terms of symptomatology, short-term treatment response, and long-term outcome.
\end{abstract}

$\mathrm{D}$ $O$ PSYCHOSES with a mixture of affective and schizophrenic symptoms constitute a separate category or are they atypical affective or schizophrenic disorders? This is an old, yet unresolved, question (Fish 1964; Coryell and Tsuang 1975; Procci 1976; Abrams and Taylor 1976; Pope and Lipinski 1978; Himmelhoch et al. 1981). The current view is that schizoaffective psychosis is not an independent category and in particular related to the affective disorders (Tsuang 1979; Tsuang and Dempsey 1979; Pope et al. 1980; Rosenthal et al. 1980). The identity issue is important. If schizoaffective psychoses were to be an independent category, yet treated as an affective disorder, much research in the latter category would be spurious.

We developed a program to study whether there is a need for the category schizoaffective disorder. The present study focuses on the question of the course of the schizoaffective psychoses and considers the following questions. (1) What are the long-term and short-term prognoses of the schizoaffective psychoses as compared with those of the schizophrenic and manic-depressive states? (2) Is the course of the schizoaffective psychoses influenced by: (a) the syndromal type, (b) possible psychogenic provocation, or (c) changes in the cerebral metabolism of 5 hydroxytryptamine (serotonin; 5-HT)?

The motivation of question $2 \mathrm{~b}$ was the following. In Scandinavia (Strömgren 1974; McCabe 1975; Anderson and Laerum 1980) and in the Netherlands (Van Dijk 1963) the term reactive or psychogenic psychosis is accepted usage. It is used with reference to functional psychoses of psychogenic origin, in which there appears to be a close correlation between the contents of the psychosis and the structure of the premorbid personality. Symptomatologically these psychoses are believed not to differ from schizophrenic and schizoaffective psychoses; but they are believed to have a more favorable course than the latter categories. This, however, has not so far been demonstrated.

The rationale behind question $2 \mathrm{c}$ was the following. In a subgroup of unipolar and bipolar vital depressions the CSF 5-HIAA concentration has been found decreased, both in baseline values (Asberg et al. 1976a) and after administration of

From the Department of Psychiatry. Albert Einstein College of Medicine/Montefiore Medical Center. and the Department of Psychiatry, Utrecht University Hospital. Utrecht. The Netherlands.

Address reprint requests to Dr van Praag at 1300 Morris Park Avenue, Bronx. NY 1046I

(c) 1984 by Grune \& Stratton. Inc. 0010-440X/84/2501-0050\$02.00/0 
probenecid (van Praag et al. 1971, 1973; Goodwin et al. 1978). 5-HIAA (5-hyroxyindoleacetic acid) is the principal metabolite of 5-HT. These 5-HT disorders would seem to exert an influence on the prognosis. The low 5-HIAA subgroup shows an increased risk of relapse (van Praag and De Haan 1979, 1980; Sedvall et al. 1980) and an increased suicide risk (Asberg et al. 1976b; Traskman et al. 1981). In other syndromal depression types and various types of psychosis we did not find more frequent 5-HT disorders than in a control group (van Praag 1982), with one exception: schizoaffective psychoses with predominantly depressive symptomatology. This raised the relevant question whether the 5-HIAA response to probenecid influences the prognosis in this category also.

\section{METHODS}

\section{Design}

In the past 15 years the probenecid-induced 5-HIAA accumulation in lumbar CSF was measured in 108 patients with functional psychoses, with a subsequent follow-up over several years. The diagnosis was 'psychosis of the schizophrenic type' in 42, and 'schizo-affective psychosis' in 66 cases. The control group consisted of 43 persons. The probenecid technique was used as been described elsewhere (van Praag 1977).

We report here on a psychopathological re-examination of these patients 4 to 7 years after the hospital period during which the CSF study was performed (the index admission). The course in the schizoaffective group was compared with that in two reference groups: the group of schizophrenic patients and a group of 50 patients with unipopular and bipolar vital depressions. In the latter group the indication for the index admission was a nonpsychotic vital depression. These patients, too, were re-evaluated after a period of 4 to 7 years. The relevant data were obtained from the attending psychiatrist (not the psychiatrist who had made the index diagnosis) or the family doctor. The following variables were studied. (1) Psychopathological condition at discharge after the index admission. (2) Number of admissions for depression, mania, schizoaffective psychosis or schizophrenia since the index period. (3) Psychopathological condition 4 to 7 years after the index period. (4) Occupational level as compared with that prior to the index period. Family history was not analyzed, since this study is retrospective and the precision by which this factor is studied by residents generally leaves much to be desired.

\section{Diagnostic Criteria}

\section{Schizoaffective Psychoses}

Within one psychotic phase and with clear consciousness, the patient shows both schizophrenic and affective symptoms, either simultaneously or alternately. The duration of the psychosis should be at least 2 weeks. Our criteria and classification differ from those given in the Research Diagnostic Criteria (Spitzer et al. 1978). The RDC strongly emphasize the affective symptoms. Our criteria are more "balanced". Moreover, the RDC apply the "choice" principle: in order to qualify for a particular diagnosis, the patient need only show a given number of a series of symptoms, regardless which. For the sake of better diagnostic homogeneity we prefer a system which links a particular diagnosis with the presence of particular symptoms. The third difference is that we believe that the symptomatological diversity of schizoaffective psychoses cannot be reflected within the two subtypes distinguished by the RDC. The following is a succinct description of the subtypes we distinguish. The validity of this classification is under investigation, and the present study can be regarded as part of this research line.

Melancholia. (a) Severe despondency in which the depressed mood has a certain quality which we describe as "unmotivated" (van Praag 1962, 1978; van Praag et al. 1965). (b) Psychomotor inhibition and/or agitation. (c) Mood-congruent delusions, sometimes also hallucinations, in which the decline of the physical (hypochondriacal delusions), the material (poverty delusions) and the spiritual existence (e.g., sin and guilt delusions) is perceived. 
We regard this syndrome as a psychotic variant of vital depression: a syndromal depression type which corresponds with major depressive disorder of the DSM III (van Praag 1962, 1978, 1982a, 1982b: van Praag et al. 1965). Melancholia is often preceded by a (nonpsychotic) vital depression

Depressive Subtype. Symptoms as in melancholia, but also mood-incongruent hallucinations and/or delusions ( $\mathrm{eg}$, delusions of being influenced of reference and of persecution). Disturbances in the cognitive functions can (but need not) occur.

Manic Subtype A. (a) Mood elated, and/or excited, and/or irritable, with diminished self-criticism. (b) Disinhibition of motor activity, level of initiative and aggressivity. (c) Mood-congruent delusions, sometimes also hallucinations which indicate marked overestimation of the patient's own significance and abilities. We regard this syndrome as a psychotic variant of the manic syndrome.

Manic Subtype B. Symptoms as in subtype A, but also mood-incongruent hallucinations and/or delusions (eg, delusions of being influenced of reference and of persecution). Disturbances in cognitive functions can (but need not) occur.

Ecstatic Subtype. (a) Blissful mood, full of the certainty of being chosen for an important mission, a significant act or a great achievement. This certainty was often attained via a sudden inspiration. (b) Mood-congruent hallucination and/or delusions ( $\mathrm{eg}$, the command of a heavenly voice: notions about an imminent marriage to a prominent person, etc.). (c) Disinhibition of cognitive and psychomotor functions and increased urge to act remain absent. Studies like the present one will have to establish whether it is meaningful to differentiate this syndrome from manic subtype A.

Schizophreniform Subtype. (a) Affective disturbances, be they depressive or manic, in which both the mood and psychomotor activity are involved. (b) Hallucinations and/or delusions of mood incongruent character. (c) Disturbances of the cognitive functions can (but need not) occur.

\section{Schizophrenic Psychoses}

We use the term schizophrenic as a collective term for psychoses in which severe disturbances can occur in perception, cognition, level of initiative, emotional responsiveness and ability to establish social contacts, while consciousness remains unclouded. Mood regulation is not severely disturbed. The duration of the psychosis is at least two weeks (van Praag 1976). The group is subdivided on the basis of differences in course.

Acute (or Benign) Schizophrenia. Adequate treatment restores the patient to the premorbid level within a maximum of 3 months. We prefer the term "benign" to "acute" because both onset and disappearance of symptoms are often subacute; however, this designation lacks tradition. This syndrome corresponds with the Schizophreniform Disorder of the DSM III, the difference being that for the latter diagnosis the duration of illness should not exceed 6 months, including the prodromal phase. We reckon the duration of illness from the onset of psychotic symptoms. The difference in time is probably quite small in actual fact-a suspicion which is confirmed by the results of this study.

When relapses occur the condition is diagnosed as recurrent acute schizophrenia.

When the patient fails to return to the premorbid level within 3 months, the following forms are distinguished.

Subchronic or Chronic Schizophrenia. The term subchronic or chronic schizophrenia is used, when predominantly positive residual symptoms (at least delusions and/or hallucinations) persist for less or more than 2 ycars. The best-fitting DSM diagnosis is Schizophrenic Disorder, Residual Type. The fitting is far from perfect, however, because this DSM diagnosis accentuates the negative symptoms: 'without any prominent psychotic symptoms'. 
Subchronic or Chronic Schizophrenic Defect State. There are negative residual symptoms (particularly inertia, contact disturbances and reduced emotional responsiveness). We diagnose subchronic or chronic schizophrenic defect state in these cases, even if positive symptoms have also persisted. The time limit likewise for these categories is 2 years. A flare-up of the positive symptoms in such a defect is described by us as psychotic exacerbation of a (sub)chronic schizophrenic defect state. These diagnoses virtually correspond with the various forms of Schizophrenic Disorder, Residual Type of the DSM III.

Unipolar and Bipolar Vital Depressions. The vital depression syndrome corresponds with the major depressive episode in the DSM III, the difference being that the DSM describes this syndrome as severe by definition, whereas our findings indicate that vital depressions can occur in all degrees of severity (van Praag 1982a, 1982b). The terms unipolar and bipolar are used as in the DSM III.

Psychosocial Precipitants. That a depression, mania or psychosis was (partly) provoked by psychosocial factors was considered plausible if the 6 months preceding the onset of psychotic symptoms had encompassed an event which was considered to have been psychotraumatic by the patient, the resident in psychiatry and an independent psychiatrist.

Short-Term Treatment Response. We used the same method as Pope et al. (1980). The short-term response was scored directly from the wording used in the resident discharge summary. Patients were divided into three categories: (1) those rated "worse", "unimproved", or "slightly improved"; (2) those rated "moderately improved"; (3) those rated "markedly improved" or "in remission".

Long-Term Outcome in Psychopathological Terms. The data obtained from the attending psychiatrist or family doctor were summarized in one of the following conclusions, the numeration of which was used as score. (1) The patient was discharged after the index admission as restored to the premorbid level, and no psychotic, depressive, or manic phases have since occurred. (2) The patient was discharged after the index admission as recovered. A phase as described in \#1 has since occurred once or several times, always followed by recovery. (3) Residual symptoms (in particular positive symptoms) have persisted after a particular admission in the index period. (4) Like \#3, but characterized by predominantly negative symptoms. (5) Positive and/or negative residual symptoms have persisted since the index admission.

\section{Long-Term Outcome in Terms of Social Functioning}

One aspect of social functioning was studied: the occupational level. The pertinent data were again summarized in five conclusions, the numeration of which was used as score.

1. The patients are able to perform independently the work they also did prior to the index admission.

2. The occupational level had diminished after a particular admission in the index period, the patients having to accept less difficult work than they previously did. Housewives have to be helped with certain domestic tasks.

3. The deterioration mentioned in \#2 became evident after the index admission.

4. The patients are no longer able to practice a profession/occupation independently. They are still productive in a protected workshop. Housewives can no longer cope with their tasks unaided.

5. The patients are no longer productive, or their work in a protected workshop is of a low level. Housewives are no longer active in domestic work.

\section{Statistical Methods}

For analysis of the data, the level of significance in all the statistical tests used was set at $P=0.05$. One-way analysis of variance according to Kruskal-Wallis was used to test difference in psychopathological status as well as in occupational level between the various patient groups. The Mann-Whitney $U$-test was applied in paired testing of the central tendency between the patient groups, making use of the approximately normal distribution of the test statistic $U$ (Siegel 1956).

The chi-square test was used to determine differences in number of admissions between acute and recurrent schizophrenia on the one hand, and chronic forms of schizophrenia on the other. 
Fisher's exact probability test was used to determine differences in incidence of demonstrable psychogenic provocation between acute (recurrent) and (sub)chronic forms of schizophrenia.

\section{RESULTS}

\section{CSF 5-HIAA}

The number of patients with a subnormal 5-HIAA response in the schizophrenic group was comparable with that in the control group (Table 1). The subnormal responses seemed to accumulate in the acute group.

The 5-HIAA response was decreased in $30 \%$ of the patients in the schizoaffective group. Subnormal responses accumulate in the categories "melancholia" (75\%) and "depressive subtype" (66\%). 5-HIAA values below 2 SD from the mean were defined as abnormal values (van Praag et al. 1973).

The SCF 5-HIAA level does not influence the long-term prognosis of schizoaffective psychoses (Table 2).

\section{Short-Term Treatment Response}

All patients in the schizophrenic group and most patients in the schizoaffective group were treated with neuroleptics. Exceptions were the melancholic and depressive subtypes, which were treated as depressions (Table 3 ).

The treatment response after 6 weeks was described as good in 12 of the 23 patients with acute (benign) forms of schizophrenia (52\%), and in 1 of the 19 patients $(5 \%)$ of the $(\mathrm{sub})$ chronic group $(\mathrm{p}<0.001)$. In the acute group, 7 of the 23 patients $(30 \%)$ were restored to the premorbid level. We set the cut-off point between acute and chronic forms at 3 months. The data in question (Table 3) demonstrate that the difference in course was already demonstrable after 6 weeks. The DSM III sets the cut-off point at 6 months. The 6 -month data were not available for all patients. Nevertheless, a significant difference in the number of marked improvements persisted between the acute and the chronic groups of schizophrenia.

In the schizoaffective group, 18 of the 23 patients $(78 \%)$ with predominantly mood-congruent delusions and/or hallucinations (melancholia, manic subtype A

Table 1.

Post-Probenecid CSF 5-HIAA in Patients With Schizophrenic and Schizoaffective Psychoses

\begin{tabular}{|c|c|c|c|}
\hline & \multirow{2}{*}{$\begin{array}{c}\text { Number of } \\
\text { Test } \\
\text { Persons }\end{array}$} & \multicolumn{2}{|c|}{$\begin{array}{c}\text { Test Persons With Low } \\
\text { 5-HIAA Values }\end{array}$} \\
\hline & & Number & $\%$ \\
\hline Schizophrenic psychoses & 42 & 6 & 14 \\
\hline Acute (benign) forms & 23 & 5 & 17 \\
\hline (Sub)chronic forms & 19 & 1 & 5 \\
\hline Schizoaffective psychoses & 66 & 20 & 30 \\
\hline Melancholia & 12 & 9 & 75 \\
\hline Manic subtype A & 7 & - & - \\
\hline Ecstatic subtype & 4 & 1 & 25 \\
\hline Depressive subtype & 12 & 8 & 66 \\
\hline Manic subtype B & 10 & - & - \\
\hline Schizophreniform subtype & 21 & 2 & 10 \\
\hline Control group & 43 & 4 & 9 \\
\hline
\end{tabular}


Table 2.

Long-term Outcome in the Melancholic and Depressive Subtypes of Schizoaffective Psychoses, With and Without Decreased CSF 5-HIAA Level After Probenecid Load

\begin{tabular}{lccc}
\hline & $\begin{array}{c}\text { Total } \\
\text { Number }\end{array}$ & $\begin{array}{c}\text { Average Score: } \\
\text { Residual } \\
\text { Pathology }\end{array}$ & $\begin{array}{c}\text { Average Score: } \\
\text { Occupational } \\
\text { Level }\end{array}$ \\
\hline Melancholia & 12 & 1.6 & 1.2 \\
Low 5-HIAA & 9 & 1.6 & 1.3 \\
Normal 5-HIAA & 3 & 1.4 & 1.2 \\
Depressive subtype & 12 & 2.3 & 2.2 \\
Low 5-HIAA & 8 & 2.0 & 1.9 \\
Normal 5-HIAA & 4 & 2.5 & 2.5 \\
\hline
\end{tabular}

and ecstatic subtype) showed marked improvement after 6 weeks. This percentage does not differ significantly from that in the manic-depressive group (66\%). The therapeutic result was "good" in 10 of the 22 patients (45\%) with manic subtype $B$ and the depressive subtype, and in 10 of the 21 patients $(48 \%)$ in the schizophreniform subgroup. The difference from the first group was significant in both cases $(P<0.05$ and $P<0.05)$. Restoration to the premorbid level was seen after 6 weeks in $48 \%, 52 \%$ and $39 \%$ of these patients, respectively. No indications were found that the different treatments used resulted in systematic differences in outcome.

\section{Long-Term Outcome}

Both the psychopathological state and the occupational level were significantly better in the acute schizophrenia groups than in the (sub)chronic groups $(P<0.01$ and $P<0.01$ ) (Tables 4,5).

In the schizoaffective group there were likewise differences, albeit less pronounced. The syndromes with delusions and/or hallucinations of the mood-congruent type (melancholia, manic subtype $\mathrm{A}$ and ecstatic subtype) took a significantly more favorable course than the subgroups with (predominantly) mood-incongruent delusions and/or hallucinations, both in terms of residual pathology and in terms of occupational level $(P<0.02$ and $P<0.01)$.

The long-term outcome in psychopathological terms in the last mentioned categories did not significantly differ from that in the group of acute (recurrent) schizophrenias. In terms of occupational level the group of the acute (recurrent) schizophrenias did better $(P<0.01)$. The long-term outcome in schizoaffective psychoses wiht mood-congruent delusions and/or hallucinations was virtually the same as that in unipolar and bipolar vital depressions.

\section{Number of Admissions}

The number of admissions before and after the index period did not signficantly differ in the groups studied (Table 6).

\section{Psychogenic Provocation}

The incidence of this factor was virtually the same in the schizophrenic, the schizoaffective and the manic-depressive group. Within the schizophrenic group psychogenic provocation was more frequently diagnosed in the acute (recurrent) 


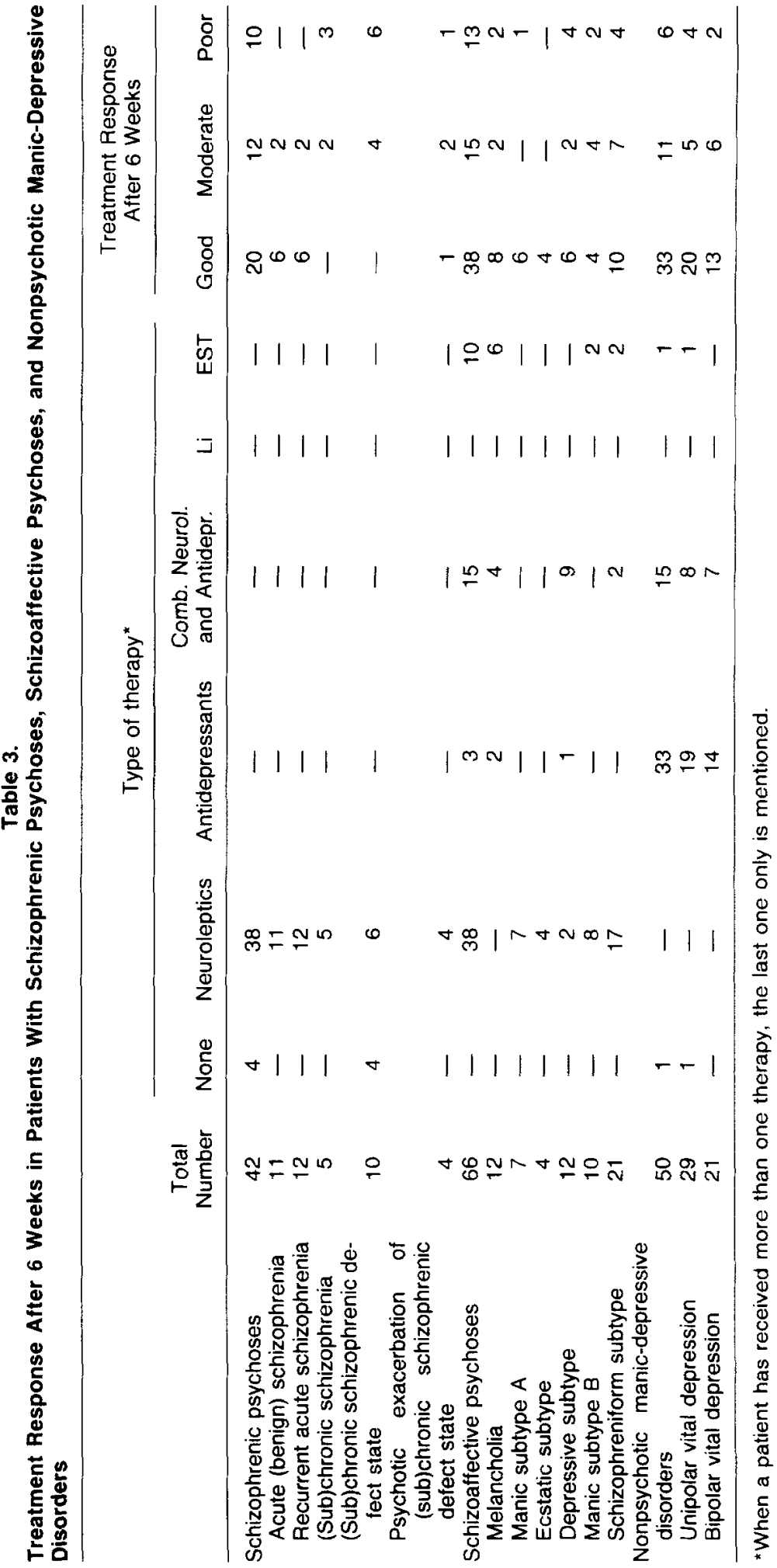




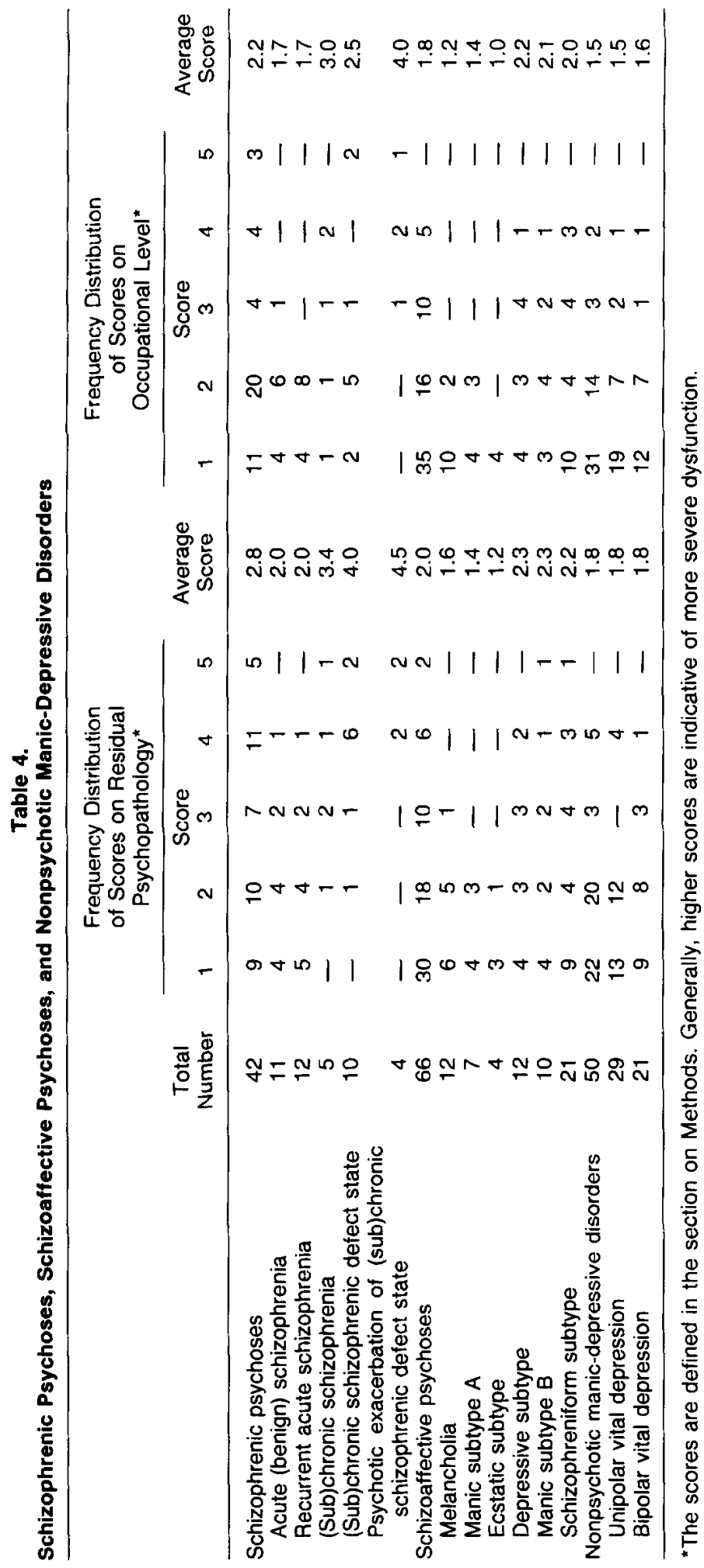


Table 5.

Evaluation of the Results Listed in Table 4, Using the Mann-Whitney U-test

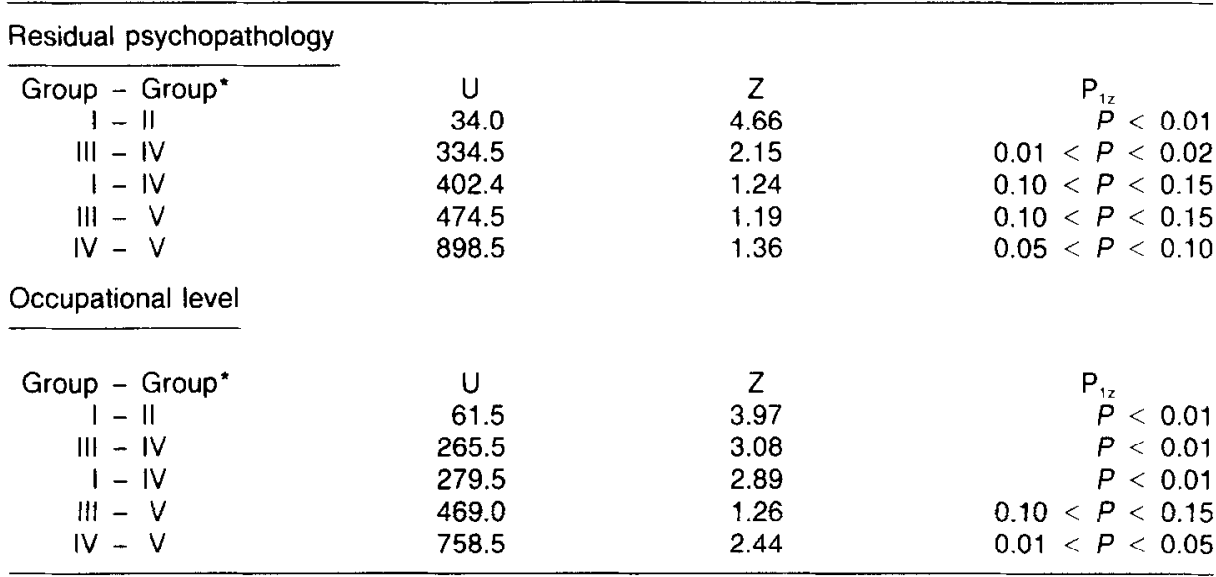

Kruskal-Wallis one-way analysis of variance over the five groups as regards residual psychopathology: $H=41.378$; $d f=4 ; P<0.01$; as regards occupational level: $H=35.789 ; d f=4 ; P<$ 0.01 . This indicates that the five groups do not originate from one population.

Group :: Acute (benign) schizophrenia and recurrent acute schizophrenia.

II: (Sub)chronic schizophrenia, three forms.

III: Melancholia, manic subtype A and ecstatic subtype.

IV: Depressive subtype, manic subtype B and schizophreniform subtype.

$\checkmark$ : Nonpsychotic manic-depressive disorders.

forms than in the (sub)chronic forms. This difference was not statistically significant. Within the schizoaffective group psychogenic provocation was virtually of the same incidence in the various subgroups, and it did not differ from that in the manicdepressive group. The long-term outcome was not influenced by the factor "psychogenic provocation", either in the schizophrenic group or in the schizoaffective group (Table 7).

\section{DISCUSSION}

This study considered the question whether the course in patients with schizoaffective psychoses differs from that in patients with (a) various types of schizophrenic psychosis, and (b) nonpsychotic unipolar and bipolar vital depressions. The prognostic criteria applied were: short-term treatment response, number of admissions before and after the index admission, and residual pathology and occupational level 4 to 7 years after the index admission (long-term outcome).

Our findings indicate that the schizoaffective group is a heterogeneous group. Schizoaffective psychoses with mood-congruent delusions and/or hallucinations show a short-term and a long-term course similar to those of the unipolar and bipolar depressions. The course is less favorable when mood-incongruent delusions and/or hallucinations become predominant. The course of these syndromes is more like that of the acute (benign) forms of schizophrenia, both in short-term treatment response and in long-term outcome. The (sub)chronic forms of schizophrenia constitute a separate group in terms of prognosis. They are defined on the basis of the unfavorable short-term treatment response. These are schizophrenic syndromes in 


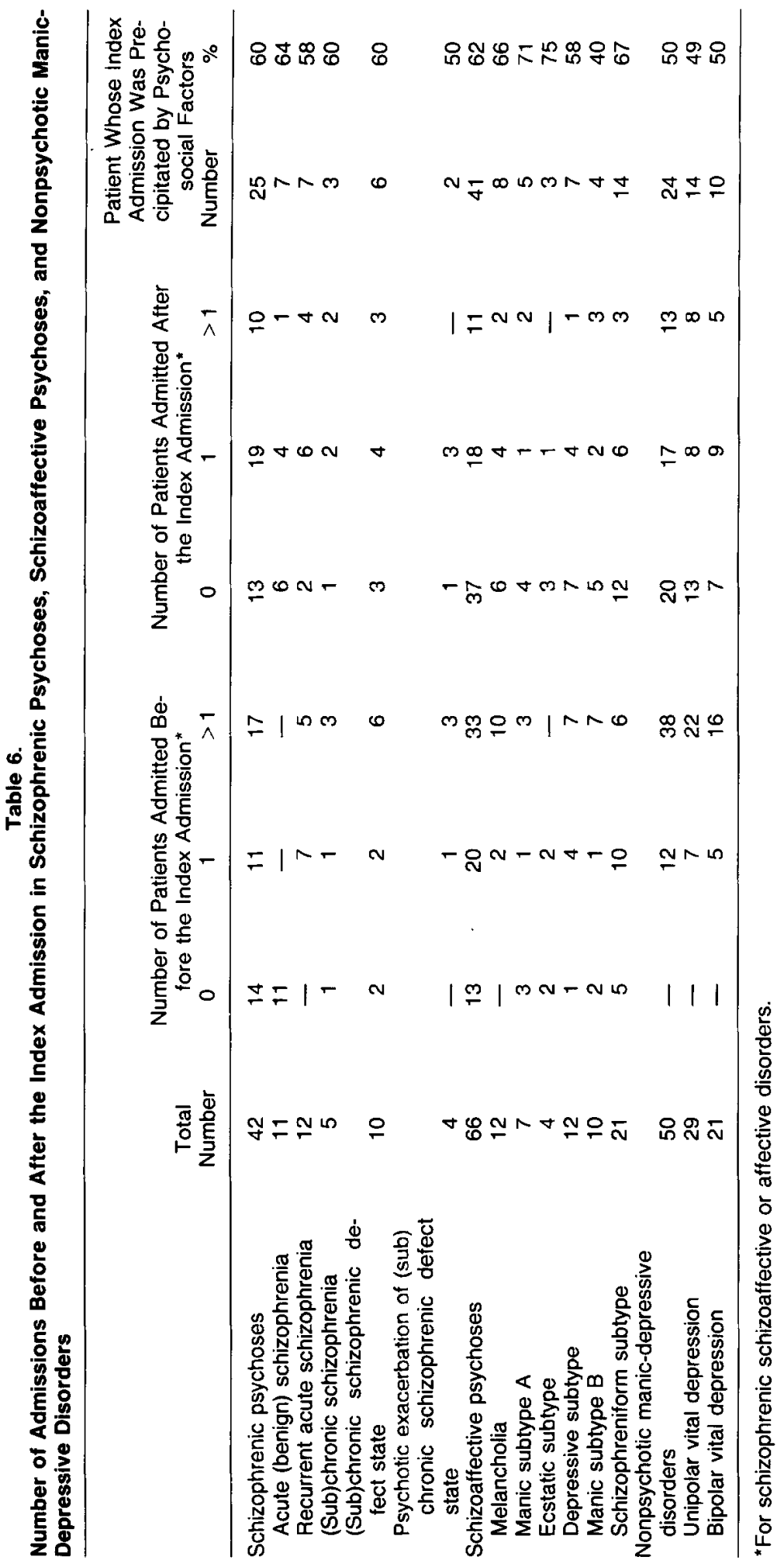




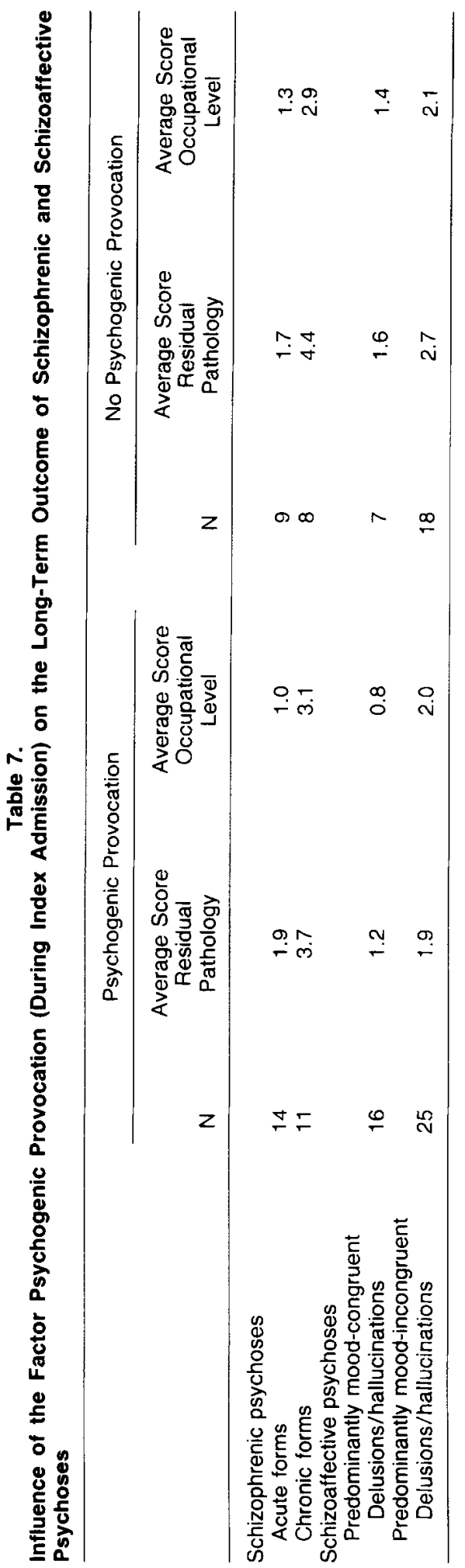


which the patient is not restored to the premorbid level after 3 months. Our data indicate that the long-term outcome in this group is likewise more unfavorable than that in all other groups studied: more residual pathology, a more marked decrease in occupational level. The acute and the chronic groups did not differ significantly in relapse rate.

Though the schizoaffective group on the whole has a considerably better prognosis than the (sub)chronic forms of schizophrenia, a by no means insignificant number of schizoaffective patients (18 out of 66) showed serious residual pathology in the long run. Recurrent schizoaffective psychosis and changes in personality structure are apparently not mutually exclusive.

The schizoaffective group is heterogeneous, not only in terms of symptomatology but also in terms of short-term and long-term prognosis. As regards the latter it partly overlaps with the acute (benign) "good-prognosis schizophrenia", and partly with the manic-depressive states.

Should the schizoaffective group therefore be denied an identity and at best allowed to exist as a repository for not readily classifiable cases, as proposed in the DSM III? We do not think so. Similarity in prognosis between two syndromes by no means excludes differences in pathogenesis or in therapeutic strategy. A century ago, pulmonary tuberculosis and pulmonary carcinoma had a comparable prognosis. They have nevertheless proved to be quite different diseases.

The schizoaffective group is symptomatologically characterized by the concomitance of affective and schizophrenic symptoms. This gives the group its identity. We again turn to an analogy with somatic medicine. A person may show symptoms suggestive of bronchitis (eg, cough, expectoration) as well as symptoms suggestive of cardiac decompensation (eg, exertional dyspnoea). It would be premature to describe these symptoms as indicating (an atypical form of) bronchitis or as (an atypical form of) cardiopathy. They might well be an expression of another disease, eg, lung cancer. Far from wishing to abolish it, we would want to uphold the schizoaffective group and make it the subject of systematic research, with careful syndrome analysis as starting-point. The present study is in part an attempt to contribute to this. The classification we propose strongly accentuates a phenomenological criterion: mood (in) congruence of delusions and/or hallucinations. No studies have been published indicating whether this distinction can be made reliably. Our preliminary findings are encouraging.

In a particular subgroup of vital depressions (van Praag and Korf 1971; Asberg et al. 1976; Goodwin et al. 1978) and in the melancholic and depressive subtype of schizoaffective psychoses (van Praag 1982) decreased CSF 5-HIAA values have been found. In vital depression this factor seems to contain predictive information. In the low 5-HIAA probands relapse rate (van Praag and de Haan 1979) and suicide risk (Traskman et al. 1981) was increased. Similar data were not found in schizoaffective psychoses. The percentage of low 5-HIAA probands, however, substantially exceeded that of normal 5-HIAA probands. This is why these findings warrant no definite conclusion. According to Davies et al. (1981) this biochemical phenomenon is especially observed in the more severe forms of vital depression. So far as the schizoaffective psychoses with predominantly depressive symptomatology can be rightly regarded as severe variants of vital depression, our observations support Davies' conclusion. 
The factor "psychogenic provocation" likewise proved to have no prognostic value. The groups with and those without psychogenic provocation did not differ either in short-term treatment response or in long-term outcome. This applied to the schizoaffective as well as to the schizophrenic group.

The data presented in this study would seem to warrant the following conclusions: (1) The term schizoaffective psychoses should be upheld as collective name for the group of the functional "mixed psychoses" between the schizophrenic group and that of the (non-psychotic) manic-depressive syndromes. (2) Like the group of schizophrenic psychoses, that of the schizoaffective psychoses is a heterogeneous group in terms of symptomatology, short-term treatment response, and long-term outcome. (3) Further research into schizoaffective psychoses should be based on syndromal differentiation within this group; the present study provides a sample of such research.

\section{SUMMARY}

The prognosis of the schizoaffective psychoses is a matter of some uncertainty. This study considers the short-term and the long-term course of these psychoses in comparison with those of schizophrenic psychoses and manic-depressive syndromes. The schizoaffective group was found to be heterogeneous in terms of longterm outcome, overlapping partly with the schizophrenic and partly with the manicdepressive group. Personality defects developed in $27 \%$ of patients. The long-term outcome was not influenced by the presence or absence of the factor "psychogenic provocation" during the index hospital admission. Decreased post-probenecid accumulation of 5-HIAA in CSF was frequently observed in the melancholic and depressive subtypes of the schizoaffective psychoses. An influence of this factor on the long-term outcome was not demonstrable. It is urged that the schizoaffective psychoses be accepted as a separate entity. Further research should be based on careful syndromal differentiation within this group, and the present study provides a sample of such research.

\section{REFERENCES}

Abrams R, Taylor MA: Mania and schizoaffective disorder, manic type: A comparison. Am J Psych 133:1445-1447, 1976

Anderson J, Laerum H: Psychogenic psychoses. A retrospective study with special reference to clinical course and prognosis. Acta Psych Scand 62:331-342, 1980

Asberg M, Thóren P, Träskman L, et al: "Serotonin depression": A biochemical subgroup within the affective disorders? Science 191:478-480, 1976a

Asberg M, Träskman L, Thóren P: 5-HIAA in the cerebrospinal fluid. A Biochemical suicide predictor? Arch Gen Psych 33:1193-1197, 1976b

Coryell W, Tsuang MT: Should non-feighner schizophrenia be classified with affective disorder? J Affect Disord 1:3-8, 1979

Davis KL, Hollister LE, Mathé AA, et al: Neuroendocrine and neurochemical measurements in depression. Am J Psych 138:1555-1562, 1981

Dijk van WK: Psychopathologische en klinische aspecten van de psychogene psychose. Thesis, Groningen, 1963

Goodwin FK, Cowdry RW, Webster MH: Predictors of drug response in the affective disorders: Toward an integrated approach. Psychopharmacology: A Generation of Progress. MA Lipton, A DiMascio, F Killam, (eds). Ravan Press, New York, 1277-1288, 1978

Himmelhoch JM, Fuchs CZ, May SJ, et al: When a schizoaffective diagnosis has meaning. J Nervous Mental Disord 169:277-282, 1981 
McCabe MS: Reactive psychoses. A clinical and genetic investigation. Acta Psych Scand Suppl 259:85-93, 1975

Pope HG, Lipinski JF: Diagnosis in schizophrenia and manic-depressive illness. Arch Gen Psych 35:811-827, 1978

Pope HG, Lipinski JF, Cohen BM, et al: "Schizoaffective disorder": An invalid diagnosis? A comparison of schizoaffective disorder, schizophrenia, and affective disorder. Am J Psych 137:921-926, 1980

Praag van HM, Uleman AM, Spitz JC: The vital syndrome interview. A structured standard interview for the recognition and registration of the vital depressive symptom complex. Psych Neurol Neurochir 68:329-346, 1965

Praag van HM, Korf J: Endogenous depressions with and without disturbances in the 5hydroxtryptamine metabolism: a biochemical classification? Psychopharmacology 19:148152,1971

Praag van HM, Korf J, Schut T: Cerebral monamines and depression. An investigation with the probenecid technique. Arch Gen Psych 28:827-831, 1973

Praag van HM: Depression and Schizophrenia. A Contribution on Their Chemical Pathologies. Spectrum Publ, New York, 1977

Praag van HM: About the impossible concept of schizophrenia. Comp Psych 17:481-497, 1976

Praag van HM: Psychotropic Drugs. A Guide for the Practitioner. Brunner/Mazel, New York, 1978

Praag van HM, De Haan S: Central serotonin metabolism and frequency of depression. Psych Res 1:219-224, 1979

Praag van HM, De Haan S: Depression vulnerability and 5-hydroxtryptophan prophylaxis. Psych Res 3:75-83, 1980

Praag van HM: Depression, suicide and serotonin metabolism in the brain. In: The neurobiology of manic depressive illness. RM Post, JC Ballenger (eds). Williams and Wilkins, Baltimore, 1983

Praag van HM: A transatlantic view of the diagnosis of depression according to the DSM III. I. Controversies and misunderstandings in depression diagnosis. Comp Psych 23:315329, 1982

Praag van HM: A transatlantic view of the diagnosis of depressions according to the DSM III. II. Did the DSM III solve the problem of depression diagnosis. Comp Psych 23:330-338, 1982

Procci WR: Schizoaffective psychoses: Fact or fiction? Arch Gen Psych 33:1167-1178, 1976

Rosenthal NE, Rosenthal LN, Stallone F, et al: Toward the validation of RDC Schizoaffective disorder. Arch Gen Psych 37:804-810, 1980

Sedvall G, Fyrö B, Gullberg B, et al: Relationships in healthy volunteers betwcen concentration of monamine metabolites in cerebrospinal fluid and family history of psychiatric morbidity. Br J Psych 136:336-374, 1980

Spitzer RL, Endicott J, Robins E: Research diagnostic criteria (RDC) for a sclected group of functional disorders, 3rd. ed. New York, Biometics Research New York State Psychiatric Institute, 1978

Strömgren E: Psychogenic psychoses, in Hirsch SR, Shepherd M, (eds): Themes and Variations in European Psychiatry. Wright, Bristol, 97-117, 1974

Träskman L, Asberg M, Bertilsson L, et al: Monamine metabolites in CSF and suicidal behavior. Arch Gen Psych 38:631-636, 1981

Tsuang MT, Dempsey M, Rauscher F: A study of "atypical schizophrenia": comparison with schizophrenia and affective disorder by sex, age and admission, precipitant, outcome, and family history. Arch Gen Psych 33:1157-1160, 1976

Tsuang MT: Schizoaffective disorder. Dead or alive. Arch Gen Psych 36:633-634, 1979

Tsuang MT, Dempsey M: Long-term outcome of major psychoses. II. Schizoaffective disorder compared with schizophrenia, affective disorders, and a surgical control group. Arch Gen Psych 36:1302-1304, 1979 